\title{
ASPECTOS IDENTITÁRIOS E CULTURAIS NA FORMAÇÃO DOS NOMES DE LUGARES: UM ESTUDO SOB A ÓTICA DA GEOGRAFIA CULTURAL E HUMANISTA
}

Aspectos la identidad cultural y la educación en los nombres de grupo doméstico: estudio bajo la óptica y geografía cultural humanista

Identity and cultural aspects in the formation of names of places: a study under the optics of cultural and humanist geography

Karylleila dos Santos Andrade ${ }^{* 1}$

${ }^{1}$ Professora dos Programas de Pós-Graduação em Letras, Universidade Federal do Tocantins, Campus de Araguaína e de Porto Nacional.

*Correspondência: Universidade Federal do Tocantins, Av. NS 15, 109 Norte, Palmas, Tocantins, Brasil. CEP:77.010-090.e-mail karylleila@uft.edu.br

\section{Artigo recebido em 02/032017. Aprovado em 22/03/2017. Publicado em 31/03/2017.}

\section{RESUMO}

A Toponímia é a disciplina que estuda os topônimos, ou seja, os nomes de lugares e está ligada à lexicologia1, ciência que pode ser definida como o estudo científico do léxico. O objetivo geral deste trabalho é identificar o papel da cultura e da identidade no processo de nomeação de lugares. Apoiar-nos-emos na abordagem da Geografia Cultural e Humanista para compreendermos, de forma mais aprofundada, a noção conceptual de lugar. A nomeação dos lugares relaciona-se diretamente com o modus vivendi dos grupos humanos, e os fatores culturais e de identidade são fundamentais nesse processo. Como percurso teórico-metodológico, utilizaremos os autores: Dick (1990, 1990a), Andrade e Bastiani (2012), Holzer (2003) e Tuan (1979, 2012).

Palavras-chave: Cultura. Identidade. Geografia Cultural e Humanista. Topônimos.

\section{ABSTRACT}

Toponymy is the discipline that studies the place names, or the names of places and is linked to lexicology, the science that can be defined as the scientific study of the lexicon. The aim of this study is to identify the role of culture and identity in the naming process places. We will support in addressing the Cultural Geography and Humanistic to understand, in more depth, the conceptual notion of place. The appointment of the places is directly related to the modus vivendi of human groups, and cultural factors and identity are essential in this process. As theoretical-methodological course, we will use the authors: Dick (1990, 1990a),Andrade e Bastiane (2012), Holzer (2003) e Tuan (1979, 2012).

Keywords: Culture. identity. Cultural Geography and Humanist. Place Names.

\section{RESUMEN}

La Toponimia es la disciplina que estudia los topónimos, o sea, los nombres de lugares y está vinculada a la lexicología, ciencia que puede ser definida como el estudio científico del léxico. El objetivo general de este trabajo es identificar el papel de la cultura y de la identidad en el proceso de nombramiento de lugares. Nos apoyaremos en el enfoque de la Geografía Cultural y Humanista, para comprender de forma más profunda la noción conceptual de lugar. El nombramiento de los lugares se relaciona directamente con o modus vivendi de los grupos

\footnotetext{
${ }^{1} \mathrm{~A}$ Lexicologia, ciência antiga, tem como objetivos básicos de estudo e análise a palavra, a categorização lexical e a estruturação do léxico. (BIDERMAN, 2001, p. 16)
} 
humanos, y los factores culturales y de identidad son fundamentales en ese proceso. Como referencia teóricametodológica, utilizaremos los autores: Dick (1990, 1990a), Andrade e Bastiani (2012), Holzer (2003) y Tuan (1979, 2012).

Palabras-Clave: Cultura. Identidad. Geografía Cultural y Humanista. Topónimos.

\section{INTRODUÇÃO}

A nomeação de lugares e de pessoas é uma prática realizada desde os primórdios da humanidade. Esse processo de nomeação possibilita a individualidade e, por conseguinte, a identificação particularizada. De acordo com suas características culturais, os povos designam, no ato de nomear, uma espécie legítima de registro, obtendo-se especificidades singulares da identificação dos lugares e das pessoas, o que possibilita maior relação de convivência no contexto social em que estão inseridos.

Os nomes são formas de representação dos lugares, e a nomeação realiza-se em constante transformação e de maneira dinâmica. Geralmente, o processo de denominação pode ser determinadopor aspectos econômicos, religiosos, políticos, sociais, culturais, linguísticos, entre outros. Tais fatores determinantes fazem com que os nomes passem por transformações e/ou se corrompam.

A língua tem o papel de representar as práticas empregadas pelo homem: explicita as atitudes, conhecimentos, crenças, valores de determinado grupo de falantes. Essas práticas são expressivamente representadas pelo léxico, de modo que os grupos batizam os ambientes ao seu redor, revelando sua cosmovisão e o modus vivendi de seu grupo.

É da natureza do indivíduo consolidar suas impressões nos ambientes habitados por ele. A Toponímia, como o estudo dos nomes de lugares, subárea da Onomástica, ciência que estuda os nomes próprios,pode estabelecer a materialização dessas impressões deixadas pelos indivíduos. Como formas de representação dos lugares, os nomes podem refletir os sentimentos vividos pelas comunidades. Nesse caso, a nomeação faz-se em constante transformação, isto é, dar-se-á de maneira dinâmica.

A metodologia empregada aqui baseia-se no plano onomasiológico de investigação, tendo como parâmetros os fundamentos teóricometodológicos propostos por Dick (1990). Para este estudo, optou-se por uma pesquisa de abordagem qualitativa do tipo descritivo. Nesse sentido, nossa intenção é realizar um estudo toponímico pelo viés da cultura e da identidade, tendo em vista que o ato de nomeação dos topônimos está intrinsecamente relacionado com os aspectos sociais e de vida dos povos, eos fatores de identidade e cultura são essenciais nesse processo. Essa relação se estabelece, em muitos casos, pela necessidade dos grupos humanos em nomear e classificar os lugares e as áreas geográficas ao seu redor.

O presente artigo se divide em duas sessões. Na primeira sessão, discutimos a noção conceptual de lugar, sob o viés da Geografia Cultural e Humanista. $\mathrm{Na}$ segunda sessão, nos pautamos na discussão a respeito da influência dos povos indígenas na descrição da geografia nacional. A seguir, apresentaremos a relação intrínseca da Geografia Cultural e Humanista em relação ao estudo dos nomes de lugares, a partir da Toponímia.

\section{NOMES DE LUGARES: UMA BREVE ABORDAGEM DA GEOGRAFIA CULTURAL E HUMANISTA}

O conceito de lugar possui várias perspectivas e definições variadas. Na Geografia é 
compreendido como determinada área ou ponto do espaço, sendo definido como espaço percebido. Nesse sentido, Suertegaray (2001, p. 07) explicita:

Lugar constitui a dimensão da existência que se manifesta através "de um cotidiano compartido entre as mais diversas pessoas, firmas, instituições-cooperação e conflito são a base da vida em comum"(Milton Santos, 1997). O conceito de lugar induz a análise geográfica a uma outra dimensão - a da existência- "pois refere-se a um tratamento geográfico do mundo vivido" (Milton Santos, 1997). Este tratamento vem assumindo diferentes dimensões. Mas o lugar pode também ser trabalhado na perspectiva de um mundo vivido, que leve em conta outras dimensões do espaço geográfico, conforme se refere Milton Santos (1997), quais sejam os objetos, as ações, a técnica, o tempo.

A Geografia é compreendida como um campo bastante vasto, e pela complexidade de suas relações divide-se em diversas especialidades. Uma delas é a Geografia Cultural, fundamentada a partir representações, ou seja, o conhecimento baseia-se nas percepções que os indivíduos têm acerca da superfície terrestre, bem como as representações compartilhadas. Ela considera o lugar como conceito fundamental para o estudo da geografia.

$\mathrm{Na}$ concepção da Geografia Humanista, o lugar é constituído como uma forma de experiência humana, a partir das vivências no espaço ${ }^{2}$. O lugar é determinado pelas relações vivenciadas pelos indivíduos em suas atividades cotidianas como estudo, trabalho, convivência familiar, dentre outros. Pelo viés da Geografia Cultural e Humanista, Holzer (2003) acredita que o espaço e o lugar são conceitos que definem a natureza da geografia. Ele explicita que:

Para Tuan "A importância do "lugar" para a geografia cultural e humanista é, ou deveria ser, óbvia. Como nós funcionais no espaço, os

\footnotetext{
${ }^{2}$ Suertegaray pensa o espaço geográfico como um todo uno e múltiplo, aberto a múltiplas conexões que se expressam através da diferentes categorias operacionais da geografia como os conceitos de paisagem, território, lugar e meio. (MAIA e ALVES 2009, p. 8).
}

lugares sujeitam-se as técnicas da anfilise espacial. Mas como um único e complexo conjunto - enraizado no passado e crescendo no futuro - e como símbolo, o lugar clama pelo entendimento humanista. Na tradição humanista, os lugares têm sido estudados a partir das perspectivas histórica e literário-artística [...]. (TUAN, 1979, p. 389, citado por HOLZER, 2003, p. 117-118)

\section{A Geografia Cultural é considerada} sociocultural, pois estabelece as vivências e as relações dos indivíduos no espaço. Isso remete à construção dos indivíduos como seres sociais, refletindo os aspectos identitários e culturais dos mesmos. Nessa perspectiva, o lugar é estabelecido a partir das experiências dos indivíduos, sendo avaliado como o lar, a cidade, a região dos mesmos.

Acreditamos que o conceito de lugar, discutido na Geografia Cultural, caminha também pelo viés da Toponímia, tendo em vista que os nomes de lugares não são fatores estranhos ou alheios aos contextos, históricos, culturais e sociais, ao considerar as substâncias ontológicas do seu meio, atreladas a sua carga significativa.

\section{A Geografia Cultural denomina os} topônimos como nomes geográficos e considera que esse estudo pode ser utilizado para a compreensão dos lugares como dimensões dos indivíduos. Nesse sentido, por exemplo, o nome pode ser compreendido como um aspecto que envolve a dimensão e/ou dominação territorial, com o surgimento de identidade(s) e significações para dado lugar.

Os nomes de lugares contemplam aspectos diretamente associados ao espaço geográfico. Incluem, em grande parte de suas ocorrências, um nome característico e uma nomeação genérica, estendida por aspectos topofílicos, históricos, etimológicos e etnográficos. Os lugares nomeados encerram ambiências experienciadas intensamente, 
como no sentido da topofilia ${ }^{3}$ relativa aos seus espaços e lugares (TUAN, 2012, p. 136). Quando é irresistível, podemos estar certos de que o lugar é o veículo de acontecimentos emocionalmente fortes, ou é percebido como um símbolo: o lugar, então, pode ser compreendido por diversas óticas. A topofilia condiz com o sentimento do povo em relação aos lugares, o que perpassa o sentido estático de lugar. Para a Toponímia, os nomes de lugares vão além do simples ato de nomear, ressaltando o sentimento de pertinência dos indivíduos, vai além do nome. Nesse viés, o lugar pode ser concebido como experiência humana.

\author{
Para Tuan (1979):
}

O lugar, na linguagem coloquial, tem dois significados: posição na sociedade e localização espacial. Mas, além destes, tem outro mais profundo: ele possui "espírito", "personalidade", existe um "sentido do lugar" (TUAN, 1979,409). Este sentido do lugar remete-se à apreciação visual ou estética, e também pela audição, olfato, paladar e tato, que exigem um contato próximo e uma longa associação com o ambiente. Tuan distinguiria a cena (scene) ou paisagem do lugar: "Uma cena pode ser um lugar, mas a cena em si não é um lugar. Faltalhe estabilidade: é da natureza de uma cena a propriedade de se alterar a partir de cada mudança de perspectiva. Uma cena é definida por sua perspectiva, enquanto que isso não é verdadeiro para o lugar: é da natureza do lugar que ele apareça como possuindo uma existência estável independente do indivíduo que o percebe." (TUAN, 1979,411 citado por HOLZER, 2003, p. 120-121).

Essa relação afetiva dos indivíduos com o lugar indica que se existimos, logo temos um lugar, pois todo espaço ocupado remete à noção de lugar.

\footnotetext{
3 A palavra "topofilia" é um neologismo, útil quando pode ser definida em sentido amplo, incluindo todos os laços afetivos dos seres humanos com o meio ambiente material. Estes diferem profundamente em intensidade, sutileza e modo de expressão. A resposta ao meio ambiente pode ser basicamente estética: em seguida, pode variar do efêmero prazer que se tem de uma vista, até a sensação de beleza, igualmente fugaz, mas muito mais intensa, que é subitamente revelada. A resposta pode ser tátil: o deleite ao sentir o ar, água, terra. Mais permanentes e mais difíceis de expressar são sentimentos que temos para com um lugar, por ser o lar, o lócus de reminiscências e o meio de se ganhar a vida. (TUAN, 2012, p. 135, 136)
}

Pode ser entendido como as ruas, os bairros, as casas, cidades, regiões, enfim os lugares designados e fixados pelas pessoas, de acordo com suas experiências, valores, significações e identidade. Em relação à representação simbólica na condição de lugar, Mello, 2011, p. 10) afirma que:

Para formação da identidade do lugar a relação entre a pessoa e toda a aura que a envolve é essencial. Experiência, símbolos, significados e permanência contribuem para forjar o sentido de lugar. As brincadeiras no espaço coletivo, a respeitabilidade e a convivência em endereços diversos, despertam um profundo sentimento de bairrofilia, sensação esta de apego, pertencimento, filiação e bem estar.

Quando atribuímos um nome a um lugar, estão impregnadas as marcas dos nomeadores, seus valores, visão de mundo, resultando em sua forma de identificação. Nesse contexto, Andrade e Dick (2012, p. 204) explicitam que:

A Geografia Cultural se apropria dos estudos da toponímia na tentativa de compreender a nomeação do lugar a partir de uma dimensão ontológica, tendo em vista os aspectos de dominação territorial, o contexto etimológico, o surgimento e a cristalização da identidade e a significação atribuída ao lugar. Os nomes de lugares e sua dimensão cultural adquirem uma pluralidade com simbolismos e identidades coresponsáveis pelas expressões dos valores individuais dentro de cada época, onde cada lugar fora sendo nomeado e ao mesmo tempo proporcionando um sentimento de pertencimento e domínio territorial.

Retomando, portanto, nossa proposta inicial de ampliação conceptual de lugar, com base em questões teóricas e metodológicas da Geografia Cultural e Humanista, reconhecemos lugar como uma dimensão de categoria analítica: motivacional, geográfica, histórica, linguística, ideológica, sociocultural, identitária. E sua extensão semântica extrapola a referencialidade, ou seja, o lugar é sentimento de pertencimento, afetividade, mundo vivido e experienciado na relação que se estabelece entre o denominador e o designatum. 
$\mathrm{Na}$ seção a seguir, apresentamos a influência dos povos indígenas no processo de descrição da geografia nacional.

\section{A IMPORTÂNCIA DOS POVOS INDÍGENAS NA DESCRIÇÃO DA GEOGRAFIA NACIONAL}

Os nomes de lugares podem ser caracterizados como uma riqueza cultural de um povo, nesse sentido cultura é entendida como algo não estático, dinâmico e mutável. Mello (2001, p. 448) salienta que:

a cultura é apreendida, é simbólica, é social. Vale dizer que a maneira de ser homem, o comportamento social, em grande parte, é aprendido. Esta parte do comportamento humano e o produto deste comportamento e deste conhecimento são denominados por nós de $<$ cultura> (grifo do autor).

Considerando as palavras do autor, cultura é entendida como um conjunto de atitudes, crenças, métodos e conhecimentos adquiridos ao longo da vida. Ainda em relação ao conceito de cultura, Malinowski (1962, p. 47) aborda que:

A cultura é um amalgama global de instituições em parte autônomas, em parte coordenadas. Ela se integra numa série de princípios tais como a comunhão de sangue por meio da procriação, a contiguidade em espaço relacionada com a cooperação; a especialização em atividades; e, último na ordem mas não menor em importância, o uso do poder na organização política. Cada cultura deve sua integridade e sua auto-suficiência ao fato de que satisfaz toda a gama de necessidades básicas, instrumentais e integrativas.

Segundo o autor, a cultura denomina-se a partir das relações sociais entre os indivíduos e o conhecimento que engloba o todo. É realizada de maneira constante por meio de um processo contínuo e vinculado à língua.

Oliveira (2001, p, 139) afirma que "a identidade cultural seria uma espécie de sentimento de pertencimento", tendo em vista que, pelo viés antropológico, identidade corresponde às experiências e as fontes de significado de um povo. Ela move os sentimentos, os valores, as crenças e diversos outros fatores presentes nas diversas comunidades, apresentando-se como reflexo da convivência humana.

Esses valores, inerentes à identidade, são estabelecidos por diversas maneiras de percepções, resultando em experiências e interpretações ímpares, pois, elas integram paisagens, sentimentos, possibilidades e manifestações. As relações que os indivíduos mantêm com os nomes de lugares ressaltam o sentimento de pertencimento, o que demonstra que conhecer o contexto histórico e a etimologia dos nomes só que podem ou não reforçar os laços afetivos adquiridos pelo lugar. Lembrando que cada indivíduo pode se relacionar de maneira diferente com o lugar: com mais ou menos sentimento de pertencimento e/ou afetividade, a depender de seus vínculos com o lugar.

Os nomes de lugares expressam, diretamente, relações entre o homem e o espaço geográfico, uma vez que o ato de nomear é essencialmente humano, estabelece vínculo social e cultural, diretamente ligado à ocupação, posse e conhecimento do local ou área nomeada. Atrelado a essas afirmações, Sapir (1969, p. 45) assinala que:

O léxico da língua é que mais nitidamente reflete o ambiente físico e social dos falantes. $\mathrm{O}$ léxico completo de uma língua pode se considerar, na verdade, como o complexo inventário de todas as ideias, interesses e ocupações que açambarcam a atenção da comunidade. Não é difícil encontrar exemplos de línguas cujo léxico traz assim o sinete do ambiente físico em que se acham situados os seus falantes.

A relação de afeto, quando estabelecida entre os indivíduos e o lugar, designa um simultâneo elo de domínio e afetividade. Relacionamo-nos esse 
vínculo com trecho da obra de Todorov (2003), denominada "A conquista da América - a questão do outro", em que ele descreve como Colombo foi nomeando os lugares por onde passava, durante o descobrimento da América.

[...] Colombo apaixona-se pela escolha dos nomes do mundo virgem que está vendo; e, assim como para ele mesmo, os nomes devem ser motivados. A motivação é estabelecida de várias maneiras. No início, há uma espécie de diagrama: a ordem cronológica dos batismos corresponde à ordem de importância dos objetos associados aos nomes. A sequência será: Deus, a Virgem Maria, o rei da Espanha, a rainha, a herdeira real. "A primeira que encontrei (trata-se de ilhas), de o nome de San Salvador, em homenagem a Sua Alta Majestade, que maravilhosamente deu-me tudo isto. Os índios chamam esta ilha de Guanaani. À segunda ilha dei o nome de Santa Maria de Concepción; à terceira, Fernandina; à quarta de Isabela; à quinta, Juana, e assim a cada uma delas dei um novo nome". Colombo sabe perfeitamente que as ilhas já têm nome, de uma certa forma, nomes naturais (mas em outra acepção do termo). As palavras dos outros, entretanto, não lhe interessam muito, e ele quer rebatizar os lugares em função do lugar que ocupam em sua descoberta, dar-lhes nomes justos; a nomeação, além disso, equivale a tomar posse. Mais tarde, os registros religioso e real já quase esgotados, recorre a uma motivação mais tradicional, por semelhança direta, que ele justifica em seguida. "Dei a esse cabo o nome de Cabo Belo, porque é realmente belo". [...] As coisas devem ter nomes que lhes convêm. Há dias em que esta obrigação deixa Colombo num estado de verdadeiro furor nominativo. (TODOROV, 2003, p. 37 e 38).

Apregoados ao sentimento de posse e de afeição aos lugares, acreditamos que a nomeação dos topônimos depende sumariamente dos aspectos abordados pelo denominador, enfatizando no ambiente o que deve ser mencionado. No processo de denominação, consideramos que a identidade e aindividualidade do lugar se confundem com a história e a memória dos povos. Para Andradee Bastiani (2012, p. 170), “O topônimo não é algo estranho ou alheio ao contexto ambiental, históricopolítico e cultural da comunidade. Ao contrário, reflete, de perto, a própria essência do ser social, caracterizado pela substância de conteúdo". Portanto, os nomes de lugares podem traduzir o simbolismo, a história, a memória, a identidade, o sentimento de posse, o afeto e as peculiaridades naturais de uma dada comunidade.

O sentimento de pertencimento a um povo, religião, cultura, região, tradição, ideologia concentram-se no processo de formação de construção identitária. A cultura e identidade formam um conjunto de relações históricas, simbólicas, sociais, patrimoniais, que determinam os valores de um povo.

O estudo dos topônimos indígenas, inerentes aos preceitos de cultura e de identidade, concretiza-se em relação à análise dos topônimos em virtude da contextualização e influência histórica no país.Esses nomes sofreram fortes influências históricas, culturais e físicas no que se referem à motivação. Para Sampaio (1987, p. 41):

Uma vez, porém, que as palavras se prestam frequentemente a diversas interpretações, convém confrontar a produção característica do lugar com o nome que tem; porquanto os indígenas escolhiam, quase sempre, os nomes das localidades, de acordo com as suas produções naturais, manifestando muitas vezes um dom de observação admirável (...). Os nomes geográficos são conhecidos e estão na boca de todos; servem eles, portanto, de ponto de partida e se tornam um auxílio que não deve ser desprezado para desenvolver a memória.

Os grupos indígenas deixaram heranças inesgotáveis de conhecimento para cultura brasileira, tendo em vista que, durante os séculos XVI e XVII, os índios representavam a maioria da população, composta em grande parte de povos tupiniquim, os quais pertenciam à família tupi-guarani, tronco-tupi.

Esses povos possuíam grande mobilidade espacial, um fator que reflete no processo de nomeação da geografia nacional. Indiscutivelmente, foi um dos povos indígenas que exerceu influênciada 
formação da sociedade brasileira, tendo em vista que as penetrações dos colonizadores dependiam dos conhecimentos indígenas, de suas habilidades, seja como caçador, pescador, agricultor, guerreiro, conhecedor dos lugares, etc.

É importante ressaltar a contribuição dos povos e línguas indígenas não só para o processo de povoamento, mas também, para a formação da cultura nacional. Diégues Júnior (1960, p. 218) afirma que:

Não é demais repetir o valor que representou para o povoador, - e isto, se de modo geral, no Brasil, muito mais, em particular, na Amazônia - a contribuição indígena no processo de ocupação humana. Foi ele guia, remeiro, canoeiro, abridor de caminhos; proporcionou o beiju de mandioca para alimentação, desvendou os mistérios da floresta; facilitou a identificação das espécies de vegetais e animais, incorporadas, desde então, ao conhecimento do colonizador com os próprios nomes aborígenes; imprimiu a sua marca na toponímia regional, denominando acidentes geográficos e centros políticos; e, assim, tornou possível fosse o território desbravado e ocupado [...].

A influência cultural do indígena continua impregnada em todo território brasileiro. O léxico indígena, mais especificamente o da língua tupi, foi um fator determinante entre os colonizadores e os grupos indígenas. Sampaio (1987, p. 41) diz que:

A predileção do brasileiro pelos nomes indígenas na denominação dos lugares é hoje tão acentuada que a toponímia primitiva vai aos poucos se restaurando e às localidades novas dão-se de preferência nomes tirados da língua dos ameríndios tupis. [...] Há aqui um sentimento nacionalista, que se quer integrado e vívido, como que a dizer que a raça americana, vencida, nem tudo se perdeu e que sem no sangue dos descendentes, a dosagem diminui a se apagar, a memória dos primitivos íncolas perdurará com os nomes dos lugares onde a civilização ostenta os seus triunfos.

No tocante às línguas indígenas, predominam dois grandes troncos no Brasil, o Tupi e o Macro-Jê. Há outras famílias linguísticas, mas que não apresentam graus de semelhanças suficientes para serem agrupados em troncos. Rodrigues (1994) classifica as línguas indígenas brasileiras nas seguintes famílias e troncos:

Tabela I. Tronco Tupi

\begin{tabular}{|c|c|}
\hline Língua & Estado \\
\hline $\begin{array}{c}\text { Família Arikém } \\
\text { Karitiána }\end{array}$ & $\mathrm{RO}$ \\
\hline $\begin{array}{l}\text { Família Jurúna } \\
\text { Juruna (Yurúna) }\end{array}$ & MT \\
\hline $\begin{array}{c}\text { Família Mondé } \\
\text { Aruá }\end{array}$ & RO \\
\hline Cinta-Larga & MT, RO \\
\hline Gavião (Ikõrõ, Digüt) & $\mathrm{RO}$ \\
\hline Mekém & RO \\
\hline Mondé (Sanamaikã, Salamãi) & RO \\
\hline Suruí (Paitér) & $\mathrm{RO}$ \\
\hline Zoró & $\mathrm{MT}, \mathrm{TO}$ \\
\hline $\begin{array}{c}\text { Família Mundurukú } \\
\text { Kuruáya }\end{array}$ & PA \\
\hline Mundurukú & PA, AM \\
\hline $\begin{array}{l}\text { Família Ramaráma } \\
\text { Arára (Urukú, Karo) }\end{array}$ & RO \\
\hline Itogapúk (Ntogapíd) & RO \\
\hline $\begin{array}{c}\text { Família Tuparí } \\
\text { Makuráp }\end{array}$ & RO \\
\hline Tuparí & $\mathrm{RO}$ \\
\hline Wayoró (Ajurú) & RO \\
\hline $\begin{array}{c}\text { Outras línguas } \\
\text { Awetí }\end{array}$ & MT \\
\hline Puruborá & RO \\
\hline Mawé (Sateré) & PA, AM \\
\hline
\end{tabular}

Fonte: RODRIGUES (1994, p. 46) (adaptada)

Tabela II. Tronco Macro-Jê

\begin{tabular}{|c|c|}
\hline Língua & Estado \\
\hline $\begin{array}{c}\text { Família Boróro } \\
\text { Boróro (Boróro Oriental, Orari) }\end{array}$ & MT \\
\hline Umutína (Barbados) & MT \\
\hline $\begin{array}{c}\text { Família Botocudo } \\
\text { Krenák, Nakrehé }\end{array}$ & MG, SP \\
\hline $\begin{array}{c}\text { Família Jê } \\
\text { Akwén (Akwe) } \\
\text { Xakriabá (Xikriabá) }\end{array}$ & MG \\
\hline Xavánte (A'we) & MT \\
\hline Xerénte (Akwe) & GO \\
\hline Apinayé & GO \\
\hline Kaiangáng (Coroado) & RS, SC, PR, SP \\
\hline$\underline{\text { Kayapó }}$ & \\
\hline Gorotíre & PA \\
\hline Kararaô & PA \\
\hline
\end{tabular}




\begin{tabular}{|c|c|}
\hline Kokraimôro & PA \\
\hline Kubenkrangnotí & PA \\
\hline Kubenkrankêgn & PA \\
\hline Menkrangnotí & PA \\
\hline Tapayúna (?) & PA \\
\hline Txukahamãe (Mentuktíre) & MT \\
\hline Xikrín (Xikri) & MT \\
\hline Kren-Akarôre & PA \\
\hline Suyá & MT \\
\hline$\frac{\text { Timbíra }}{\text { Canela Apâniekra }}$ & MT \\
\hline Canela Rramkókamekra & MA \\
\hline Gavião do Pará (Parakáteye) & MA \\
\hline Gavião do Maranhão (Pukobyé) & PA \\
\hline Krahô & GO \\
\hline Kreyé (Krenjé) & MA \\
\hline Krikatí (Krinkati) & MA \\
\hline Xakléng (Aweikoma) & $\mathrm{SC}$ \\
\hline $\begin{array}{c}\text { Família Karajá } \\
\text { Javaé }\end{array}$ & GO \\
\hline Karajá & $\mathrm{GO}, \mathrm{MT}$ \\
\hline Xambioá & GO \\
\hline $\begin{array}{c}\text { Família Maxakalí } \\
\text { Maxacalí }\end{array}$ & MG \\
\hline Pataxó & BA \\
\hline Pataxó Hãhãhãe & BA \\
\hline $\begin{array}{c}\text { Outras línguas } \\
\text { Guató }\end{array}$ & MS \\
\hline Ofayé (Ofayé-Xavánte) & MS \\
\hline Rikbaktsá (Erikbaktsá, Arikpaktsá) & MT \\
\hline Yatê (Fulniô, Karnijó) & PE \\
\hline
\end{tabular}

Fonte: RODRIGUES (1994, p. 56) (adaptada)

Tabela III. Línguas Isoladas

\begin{tabular}{|c|c|}
\hline $\begin{array}{c}\text { Língua } \\
\text { Aikaná (Aikanã, Huarí, Masaká, } \\
\text { Tubarão, Kasupá, Mundé, Corumbiara) }\end{array}$ & Rstado \\
\hline Arikapú & RO \\
\hline Awakê & RR \\
\hline Irántxe (Iránxe; Mynky, Münkü) & MT \\
\hline Jubutí & RO \\
\hline Kanoê (Kapixaná) & RO \\
\hline Koaiá & RO \\
\hline Máku & RR \\
\hline Trumái & MT \\
\hline Tukuná (Tikúna) & AM \\
\hline
\end{tabular}

Fonte: RODRIGUES (1994, p. 98) (adaptada)
Segundo Sampaio (1987), na época das bandeira, a língua falada era o tupi.

E se, por toda a parte onde penetravam, estendiam os domínios de Portugal, não lhe propagavam, todavia, a língua, a qual, só mais tarde, se introduzia com o progresso da administração, com o comércio e os melhoramentos (p. 71).

O fato é que, por todo o sertão, o tupi predominou na formação da Toponímia brasileira. Recebiam nomes de origem tupi os lugares, elementos principalmente de procedência da natureza circundante, mesmo que não houvesse traços de qualquer povo tupi. A conservação dar-se-ia a partir da "descoberta" cujo processo de consolidação se efetivaria com o tempo ou, até mesmo, com o registro em documentos da época. "E assim é que, no Planalto Central, onde dominam povos de outras raças, as denominações dos vales, rios e montanhas e até povoações são pela maior parte da língua geral" (Sampaio, 1987, pp. 71). É o que podemos identificar na Toponímia do estado do Tocantins atualmente nos nomes dos municípios: Tupirama, Tupiratins, Tocantínea, Tocantinópolis, Gurupi, Cariri, Dueré, Itaguatins, Itacajá, Goiatins, Araguaína, Araguatins, Araguaçu, Arapoema, entre outros.

Rodrigues (1994) considera que as línguas dos povos indígenas do Brasil se adequam às expressões individuais e sociais no meio físico e social em que tradicionalmente esses povos têm vivido.

De acordo com Andrade e Bastiani (2012, p. 170):

Se considerarmos a dimensão social da língua, podemos ver, no léxico, o patrimônio cultural de uma comunidade. Transmitidos de geração a geração como "signos operacionais". É através dos "nomes" que o homem exerce a sua capacidade de exprimir sentimentos e ideias, de "cristalizar" conceitos. O patrimônio lexical de uma língua constitui um arquivo que reflete percepções e experiências multisseculares de um povo, podendo, por isso, ser considerado testemunho de uma época. 
Muitos vocábulos do português, falados no Brasil, são de origem tupi: nomes de plantas (sucupira, piqui, pitanga etc), rios (Araguaia, Tocantins, Pará etc), animais (jacaré, jaguatirica, pium, etc. Os nomes de procedência tupi foram cristalizados no léxico, em nível de sistema, ao longo dos séculos, compondo o patrimônio lexical brasileiro. É possível afirmar que as características físicas do ambiente são as principais vias de motivação para as nominações. Dick (1990a, p. 39) complementa:

O sistema léxico tupi, como reflexo de uma sociedade de economia mista, deixou uma gama variada de contribuição linguística ao português, que preservou, nos vocábulos fossilizados, as características de uma realidade ambiental diversificada ou de múltiplos domínios de experiência. Se muitos desses designativos, hoje, escapam o linguajar corrente do brasileiro, impulsionado, constantemente, pela dinâmica da língua, outro tanto não ocorre na Toponímia, que se vale deles como fonte contínua de motivação, mantendo, assim, vivas, as tradições culturais indígenas.

Para Sampaio (1987), não há quem desconheça a predominância do tupi em nossas denominações geográficas: seja nas montanhas, rios, cidades, ou nos simples povoados. Nesse contexto, Dick (1990, p. 8) argumenta que:

Como dizia Theodoro Sampaio, o indígena fazia uso globalmente, de elementos descritivos do seu ambiente - - e, completamos, empregando a terminologia de Stewart, não apenas dos descritivos puros, mas também dos descritivos associativos - porque portador de uma visão prática e objetiva.

Os estudos dos nomes de origem indígena não se limitaram apenas aos nomes de origem tupi. Levy Cardoso (1961, p. 89) realizou estudos de outros dialetos indígenas:

O principal motivo de meu interesse pelos étimos não tupis da toponímia brasílica, sobretudo pelos seus étimos caribes, aruacos e borôros, foi o fato do quase absoluto desconhecimento, por parte de nossos estudiosos, dos dialetos brasílicos fora do grupo linguístico tupi-guarani.

Os nomes de lugares geralmente são atribuídos a alguma característica física ou humana, relativos ao lúdico ou ao simbólico do povo que habitou determinado lugar, e remetem as características destes lugares, sejam elas culturais, históricas, físicas, econômicas. Como afirma Sapir (1969), "há uma forte tendência em atribuir muitos elementos da cultura humana à influência do ambiente em que se acham situados os participantes dessa cultura". Em virtude disso, os topônimos e sua dimensão cultural adquirem uma pluralidade com simbolismos e identidades corresponsáveis pelas expressões dos valores individuais dentro de cada época, onde cada lugar fora sendo nomeado e ao mesmo tempo proporcionando um sentimento de pertencimento e domínio territorial.

\section{CONSIDERAÇÕES FINAIS}

Tendo em vista as discussões da Geografia Cultural e Humanista, acreditamos no alargamento conceptual de lugar como noção de sentimento de pertencimento, afetividade, mundo vivido e experienciado. Tuan fala em amor humano ou topofília: "laços afetivos dos seres humanos com o meio ambiente material (2012, p.135)". Quando nos referimos a "sentimento de pertencimento e afetividade", entendemos "pertencer" como fazer parte de alguma coisa, ter relação com, ter vínculo com, ser proveniente, próprio de; e "afeiçoar", estima, apreço, consideração. $\mathrm{O}$ sentimento de pertencimento é o sentimento de ter vínculo, ligação, com um determinado lugar, grupo, história. E a afeição se vale do sentimento de apego, sincero, por alguém ou algo, afeiçoamento, que também pode ser 
entendido como relação, conexão. Segundo Tuan (2012, p. 136), “os pertences de uma pessoa são uma extensão de sua personalidade; ser privado deles é diminuir seu valor como ser humano, na sua própria estimação.

A partir da discussão acerca da importância dos indígenas na descrição da geografia nacional, acreditamos que os povos indígenas influenciaram não só na formação toponímica, mas também na formação da cultura e da memória nacional.

É recorrente o fato de que quando os europeus chegaram à costa brasileira, no início do século XVI, já havia diversos grupos indígenas, com os quais mantiveram seus encontros e confrontos, dentre eles: Tamoio, Tupinambá, Tupiniquim, Tabajara, Goitacaz, Goianaz, Carijó entre outros. Foram eles os tradutores das primeiras informações aos colonizadores a respeito da natureza, de outros povos, bem como, da Toponímia local indígena, embora essa não tenha sido aceita no primeiro momento. A terra "descoberta" era, para o invasor, um grande vazio onomástico a ser preenchido, e o sagrado foi a primeira opção, dada às ordens da Coroa e da hegemônica Igreja Católica.

Desse modo, os nomes de lugares não estão à sombra ou desvinculados aos contextos sociais, políticos, históricos, geográfico, ambientais e culturais dos grupos, eles refletem e retratam a natureza das comunidades em sua totalidade.

Reconhecemos, portanto, o nome de lugarcomo sendo um patrimônio linguístico e cultural, testemunho de uma comunidade. Materializado e corporificado, o nome é um produto e o reflexo social e cultural da cosmovisão de um grupo. Citando Fonseca (1997, p. 18), como referentes de uma realidade nomeada, objetos de uma cultura, os topônimos podem ser concebidos, de acordo como um centro político-social a partir do qual se organiza culturalmente um espaço geográfico, sendo a nomeação de entidades geográficas uma manifestação específica do poder organizador que um grupo exerce sobre a paisagem geográfica.

Todos os autores declararam não haver qualquer potencial conflito de interesses referente a este artigo.

\section{REFERÊNCIAS}

ANDRADE Karylleila dos S.; BASTIANI, Carla. Viajantes naturalistas do século XIX na região da Província de Goiás: levantamento de topônimos indígenas. ANTARES, vol.4, $\mathrm{n}^{\circ} 8$, p. 169-184, jul./dez. 2012.

ANDRADE Karylleila dos S; DICK, Maria Vicentina de Paula do Amaral. A interdisciplinaridade no contexto da toponímia: reflexões iniciais de uma proposta aplicada ao ensino. In: ISQUERDO, Maria Aparecida; SEABRA, Maria Cândida T. C.

de. Ciências do léxico. V. VI. Campo Grande: UFMS, 2012.

BIDERMAN, Maria Tereza Camargo. As Ciências do Léxico. In: Ana Maria Pinto Pires de Oliveira; Aparecida Negri Isquerdo. (Org.). As ciências do léxico: lexicologia, lexicografia, terminologia, $2^{\mathrm{a}} \mathrm{ed}$. Campo Grande: UFMS, 2001.

CARDOSO, Levi Armando. Toponímia brasílica. Rio de Janeiro: Biblioteca do Exército, 1961.

DICK, Maria. Vicentina de Paula do Amaral. A motivação toponímica e a realidade brasileira. São Paulo: Arquivo do estado de SP, 1990.

Toponímia e antroponímia no Brasil: Coletânea de estudos. 2. ed. São Paulo: FFLCH/USP, 1990a.

DIÉGUES, Manuel Júnior. Regiões Culturais do Brasil. Vol 2. Rio de Janeiro: Centro Brasileiro de Pesquisas Educacionais INEP. Ministério da Educação e Cultura, 1960.

FONSECA, Gustavo Solis. La gente pasa, los nombres quedan... Introduccíon em la toponímia. Lengua e Sociedade: Lima, 1997.

HOLZER, Werther. O conceito de lugar na geografia cultural-humanista: uma contribuição para a geografia contemporânea. Geografia -Ano V - n. 10, p.113-123, 2003. 
MAIA, Adriano Corrêa; ALVES Flamarion Dutra. Categorias e epistemologia: Reflexões teóricometodológicas na ciência geográfica. in V Encontro de Grupos de pesquisa "Agricultura, Desenvolvimento Regional e Transformações Socioespaciais 25, 26, 27 de novembro de 2009. UFSM - Universidade Federal de Santa Maria.

MALINOWSKI, Bronislaw. Uma Teoria Científica da Cultura. Rio de Janeiro: Zahar Editores, 1962.

MELLO. João Baptista Ferreira de. A humanística perspectiva do espaço e do lugar. Revista ACTA Geográfica, Ano V, n. 9, jan./jun. de 2011. p. 07-14.

OLIVEIRA, Pérsio Santos. Introdução à sociologia. São Paulo: Ática, 2001.

RODRIGUES, Aryon Dall'igna. Línguas Brasileiras: Para o conhecimento das línguas indígenas. 2. ed. São Paulo: Edições Loyola, 1994.

SAMPAIO, Theodoro.O tupi na geografia nacional. 5. ed. Corrigida e aumentada. São Paulo: Ed. Nacional, 1987.

SAPIR. Edward. Linguística como ciência. Rio de Janeiro: Livraria Acadêmica, 1969.

SUERTEGARAY, Dirce Maria Antunes. Espaço geográfico uno e múltiplo.Scripta NovaRevista Electrónica de Geografía y Ciencias Cociales, Barcelona, Universidad de Barcelona, n. 93, 15 de julio de 2001. Disponível em: <http://www.ub.edu/geocrit/sn-96.htm>. Acesso em: 23 out. 2014

TODOROV, Tzvetan, tradução: Beatriz Perrone Moisés. A conquista da América - a questão do outro. São Paulo: Martins Fontes, 2003.

TUAN, Yi-Fu, tradução: Lívia de Oliveira. Topofilia: Um estudo da percepção, atitudes e valores do meio ambiente. Londrina: Eduel, 2012. 